\title{
Health Policy Reform Poor Rural Primary Health Care Delivery in Australia
}

\author{
Mu Yuexuan \\ School of Public Health, Li Ka Shing Faculty of Medicine, the University of Hong Kong, China
}

Corresponding Author email: muyuexuan0331@163.com

Keywords: Diagnostic tree; health policy reform; theoretical constructs

\begin{abstract}
Rural and remote areas around the world face the challenge of global development and global capitalis. As a result, young people at working age poured into the metropolitan and urban areas and older people are left in the peripheral rural communities. Comparing with the urban population, rural residents have higher risks of preventable diseases such as diabetes, cancer and obesity, also rural communities have high rate of unhealthy behaviors such as poor diet, physical inactivity and smoking.
\end{abstract}

\section{Introduction}

Australia has a vast territory with a population of about 22 million, of which 3.5 million are distributed in 1,500 small rural and remote communities with an area of 7.5 million square kilometers. Isolated rural communities across Australia are experiencing an ageing population and a growing burden of chronic diseases (5). As families move to the big cities, the population shrinks (6). In addition, because of service infrastructure shortage, transportation difficulties and a lack of medical staff, rural residents have to give up treatment or rely on irregular doctor visiting although many rural communities are working to maintain viable comprehensive medical services. So, rural communities have significant health service troubles (7).

Primary health care (PHC) was defined by the World Health Organization refers to the essential health care. PHC is the health reform approach which focuses on health equity and includes all areas which can influence the health such as environment, lifestyle and the health service accessibility (8, 9).

In Australia, rural health care policy is driven by the corporation between Commonwealth (Federal), State or Territory and Local Government (10). Through the document "National Strategic Framework for Rural and Remote Health” published in 2012, it can be identified that the government try to promote the equal health condition to people among the rural and urban areas (11). The delivery of rural health care is provided through private, community and public hospitals in Australia. However, it has showed that the health condition in rural areas is qualitatively and quantitatively different to those in urban areas (12). Through the survey, in Australia, residents in rural communities have poorer access to primary health service than people in metropolitan cities (13). These health disparities can be caused by the gap in health resource accessibility, economic level and technical level. These all lead to the conflicts between the ethical demand, economic supply and politic values. The rural primary health care target at the rural communities, to promote equitable provision of health care services that may lead to improved health outcomes, it is necessary to discover the reasons behind the poor performance of rural primary health care in Australia and come up with the health reform approaches which can balance the ethical, economic and politics theories.

\section{Context}

\subsection{Diagnostic tree of the poor rural primary health delivery}

To balance the theories behind this problem, it is necessary to identify the cause of the poor 
primary health care delivery in rural areas through the diagnostic tree. To construct the diagnostic tree, the three possible causes can be contributed to the poor primary care in the rural areas: health system issues, aging population and characteristic of rural locale. However, the aging problem is the irreversible trend so it may not be the significant aspect of health reform. The characteristics of rural areas need concrete analysis because it is not common in all rural communities. Therefore, it is essential to analyze the health system issues and set it as the main direction of the health reform.

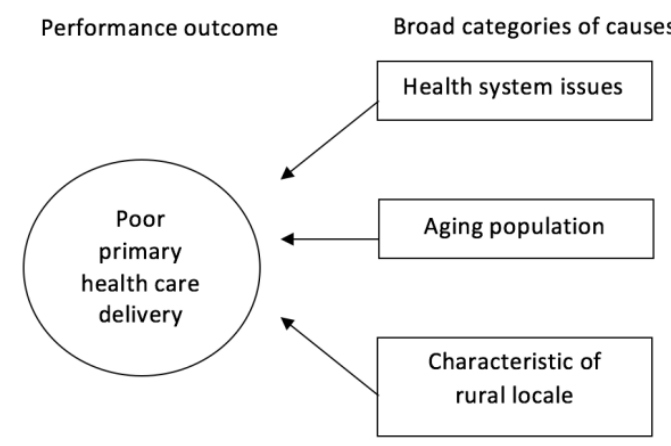

Fig.1

To keep track of the reasoning, the "health system issues" can be dividend in three dimensions: poor management, small team of health professionals and inadequate health resource. These three factors both influence the quality and quantity of rural primary health delivery.

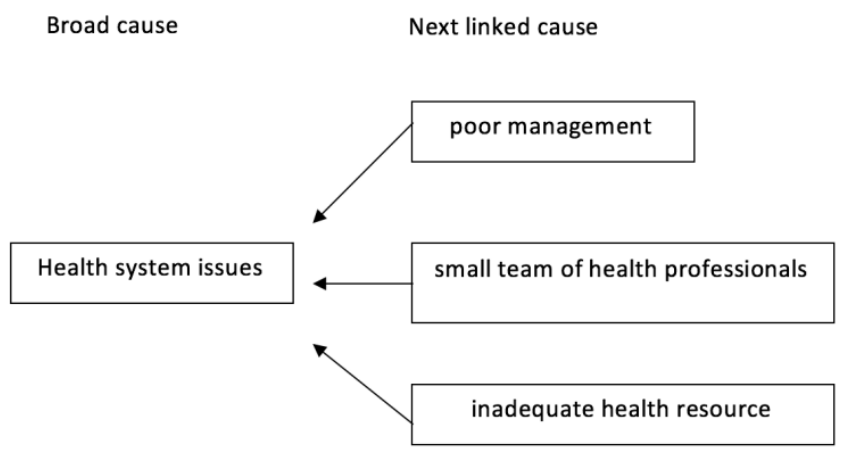

Fig.2

\subsection{Small team of health professionals}

First, small team of health professionals reflect the shortage of the primary health care providers, however, primary care physicians are the essential factors in the rural primary health care delivery. Physicians shortage is a common phenomenon in the rural areas around the world, not only in Australia, for example, about $20 \%$ of the Americans live in the rural areas while there is only about $9 \%$ of nation's physicians working in the rural areas(14). Many reasons can lead to this shortage. The recent graduated medical students are accustomed to urban life and are not willing to live in the rural communities because the medical university always in the urban areas and rural life is low standard and the payment is low(15). Also, the old physicians used in the rural community have to retire. On top of that, a shortage of staff has led doctors to have relatively excessive workload and high on-call ratio, so that, existing physicians are reluctant to insist in the rural communities (16). These reasons both contribute to the lack of physicians and this shortage can directly influence the quality of health care delivery and patients are unable to get treatment on time. 


\subsection{Poor management in the rural primary health care delivery}

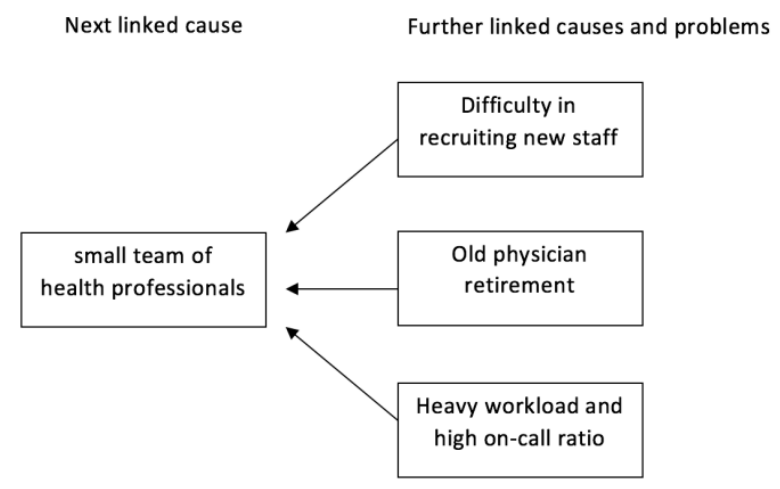

Fig.3

Second, for primary health leaders, effective health care leadership is the ability to allocate the health resource, identify problems, come up with solutions and strategies, supervise implementation process (17). Poor policy analysis, shortage of effective resource planning and inappropriate program implementation can be the reasons for the failure of rural primary health care delivery management. The poor leadership in the rural primary care delivery influence the manner in which the rural residents have access to health care. Poor management may lead to the inefficient health care system, this could also cause the ineffective oversight and corruption practices in primary health care system (17). The corruption may lead to physicians' misconduct such as asking for bribes before the treatment, also, corruption can cause the counterfeit and expired drugs to pour into the health-care system. Low quality doctors and inferior counterfeit drugs directly lead to the failure of health care delivery. It is serial effect in political because of poor management. Rural primary health care delivery have its own political values and poor management may be one of the political challenges.

\subsection{Inadequate resource in the delivery process}

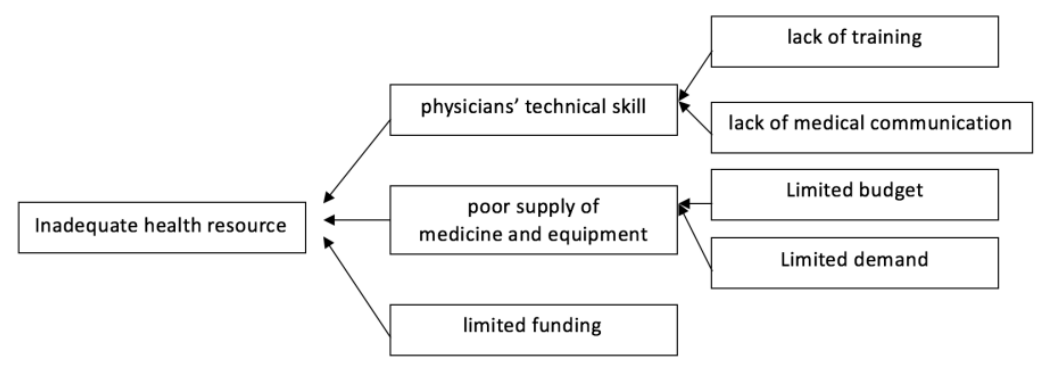

Fig.4

Inadequate resources in the delivery process contains three dimensions: physicians' technical skill, poor supply of medicine and health related equipment and limited funding from local government and other stakeholders. The physicians' skill is essential in poor primary care delivery system. Rural patients in Australia are facing aging challenge and these senior people are more susceptible than young people because of a declining body function. With a high risk of chronic disease and other age-related disease, rural seniors need to be treated more carefully under superb medical skills and nursing skill. However, due to the lack of training and medical communication, the primary care nurses and physicians have low level of skill comparing to the urban. This would lead to the rural patients' low satisfaction and reduce the trust in the doctors which is the threaten to the primary health care delivery.

Rural residents may have low health treatment under the price barrier because of the living standard, people have rights to choose whether to see a doctor. The supply of medicine would decrease if the rural residents seldom seek for the treatment. Also, the limited budget of health 
financing is the main problem and reason of the shortage of medicine and equipment. It is impossible to buy medical equipment and medicine without money. Government financial has its own plan and political use and health expenditure always pour more on urban primary health care reform. Apart from the funding from government, the related stakeholders are more willing to invest in urban health care development under cost-benefit analysis. The opportunity cost of invest in rural areas will be higher than investing in urban cities so the stakeholders would choose urban cities.

\section{Competing or conflicting theoretical constructs}

\subsection{Ethical theory}

There are three main theories in ethical theory including utilitarianism, liberalism and communitarianism. The main conflicting theory in the rural primary health care in Australia is the liberalism theory which focus on the rights and opportunities. The egalitarian liberalism holds the view that it is meaningless for the right of choosing with the inadequate resource. To ensure the equality of the health care service opportunity, every resident in the rural areas ought to have a positive right to a minimum of service and medical resources. However, in the rural areas, the quantity of treatment service they received is inferior to the urban cities.

The utilitarianism theory is to seek to use resources efficiently to produce the most "good".

When we need to judge this health policy, it should add up all people's utility level to test if this decision can lead to the most utility or happiness. The economists use the cost-benefit analysis to identify which action has the most utility. It is necessary to evaluate the cost and benefits in advance because the cost of this policy implement represent the benefits we have to give up. However, it is difficult to determine the willingness of people to pay for health service.

\subsection{Economic theory}

In health care market, it lacks characteristics that can reflect the market price which represent the economic value of the health resource (18). The pursuit of effective and fair service delivery, economic theory would focus on the resource allocation and welfare improvement. From the viewpoint of economics, the primary health care can be cost-effectiveness because the diminishing returns. The rising costs and a limited capacity to pay can raise the awareness of politicians which may lead to cost-performance dilemma. Cost is the major factor in the health policy reform under the economic system because the availability of funds is a challenge for the reformer.

\subsection{Political theory}

Rational choice theory is to make optimal and seasoned choose for solving the problem or achieving the goal. Rational Choice Theory presumes that individuals' choice for the problem is representative of larger group so it always begins with the consideration of individual decision-making units' choice behavior (19). Although individuals cannot control all the relevant factors, the choice they made that can best help achieve the goals (20). Given the presence of constraints and environmental assumptions, the equilibrium situation can be created that each agent is subject to constraints with optimal choices.

From the demand side, treatment cost is the determining factor in individual's choice of health care. From the supply side, the skills of health care provider and the amount of effective medical resource are the major constraints to the sound rural primary health care delivery. Rural residents' choice of primary health care depends on the maximum utility of primary health care system. Hence, the success of health care delivery can be influenced by quality and quantity of health care, accessibility and availability, the treatment cost. According to this, the policy should maximize the utility of the resource to improve the rural people's health care choice so that it can benefit the delivery system because these factors can determine the preferences of rural people. 


\subsection{Health policy reform strategies}

Reconciling the theories and improving the rural primary health care delivery system can be transferred into the primary health care system reform which the aim is to balance the efficiency and equality. To conduct the solutions, it is essential to identify the stakeholders involved in the primary health care delivery system. Through the identification of stakeholders, it is helpful to set up reform strategies of resource and funding allocation which are the conflicts between the economic and ethical theories.

There are three stages in the process of stakeholder analysis. First, it is necessary to identify the relevant groups and individuals which is the players in the primary health care policy. In the rural primary health care delivery process, according to the part of interest group analysis, the producer group include the physicians, nurses and other primary care providers, state and Australian Government departments, local councils. Because this policy problem targets the rural residents in the Australia, this group is the consumer group. The economic group includes the business affected by primary health care policy such as medical device industries, drug sellers. Ideological groups. The health-development groups contain nongovernmental development organizations, international health organization and other non-profit associations.

To improve the efficiency and inequality, balance three dimensions of supported theories, the first strategy should focus on maximizing performance within the current budget. From the point of politics, it is not wisdom to largely increase the funds for primary health service with giving up the investment in other projects. However, through subjective utilitarianism theory, the appropriate cost of health sector depends on consumer satisfaction, then, the health cost may not be appropriate with the result of poor delivery in Australia.

Stakeholder engagement may be the better choice to tackle the conflicts between efficiency and equality. Engaging with the local primary health care community and clinical advisory councils and city hospital, sharing the electronic medical records of rural patients and medical skills training, these would improve health service performance without increasing too much budgets. Also, rural residents can have more opportunity to receive the same high quality of health care as the urban population. It balances the liberalism ethical theory and rational choice theory to some extend because it makes primary health care become optimal choice for rural population. For example, setting up the link with urban hospital and international health organization to perform remote medical system under the sharing electronic medical records. This can create a win-win situation for primary health care system and consumer satisfaction.

The second strategy can focus on the management reform to create public transparent management system. Ethical value and political attitudes can deeply influence decision-making and political discourse. The transparency means that the process of policy decision making, medicine and health care service delivery are open to the public. Transparent system would foster trust and help consumers know more about primary health care delivery to overcome the information barriers so that patients can make the rational choice from the demand side. Also, the transparent system can improve the quality of the service under the public monitoring.

\section{Conclusion}

Poor rural primary health care delivery system limited quality and quantity of health service, remote environment and a high prevalence of aging-related diseases. To balance the equality and efficiency, the policy reform should integrate the ethical, economic and political theory. The stakeholder engagement and transparent system can improve the quality of health service under limited funds and avoid management failure so that the rural primary health delivery would earn more consumer satisfaction. 


\section{References}

[1] Harvey D. A brief history of neoliberalism: Oxford University Press, USA; 2007.

[2] Publishing O. The new rural paradigm: Policies and Governance: Organisation for Economic Co-operation and Development; 2006.

[3] Eberhardt MS, Pamuk ER. The Importance of Place of Residence: Examining Health in Rural and Nonrural Areas. American Journal of Public Health. 2004; 94(10):1682-6.

[4] Hartley D. Rural Health Disparities, Population Health, and Rural Culture. American Journal of Public Health. 2004; 94(10):1675-8.

[5] National Health and Hospitals Reform Commission: A Healthier Future For All Australians Final Report of the National Health and Hospitals Reform Commission In: Australia Co, editor. 2009.

[6] Humphreys J. Health service models in rural and remote Australia. The New Rural Health: An Australian Text. 2002:273-96.

[7] Bullock S. Whose health? How population groups vary. Australia’s Health 2010. 2010.

[8] Starfield B. Politics, primary healthcare and health: was Virchow right? Journal of Epidemiology and Community Health. 2011; 65(8):653.

[9] Cueto M. The ORIGINS of Primary Health Care and SELECTIVE Primary Health Care. American Journal of Public Health. 2004; 94(11):1864-74.

[10] Davies GP PD, McDonald J, Williams A. Integrated primary health care in Australia. International Journal of Integrated Care. 2009;9(4).

[11] Committee AHMACARHS. The National Strategic Framework for Rural and Remote Health, 2012.

[12] Rickards L. 'Rural health: problems, prevention and positive outcomes', in H. Sykes (ed.), Health, Albert Park, Vic. Future Leaders. 2011:pp.149-73.

[13] Thomas SL, Wakerman J, Humphreys JS. What core primary health care services should be available to Australians living in rural and remote communities? BMC Family Practice. 2014; 15(1):143.

[14] Rosenblatt RA, Hart LG. Physicians and rural America. Western Journal of Medicine. 2000; 173(5):348-51.

[15] Ballance D KD, Evans P. Factors that influence physicians to practice in rural locations: a review and commentary. J Rural Health. 2009:25(3):276-81.

[16] Bourke L, Humphreys JS, Wakerman J, Taylor J. Understanding rural and remote health: A framework for analysis in Australia. Health \& Place. 2012; 18(3):496-503.

[17] Raymond O. Chimezie PD, FRSPH. Failure of Primary Healthcare Delivery in Africa. International Journal of Interdisciplinary and Multidisciplinary Studies (IJIMS). 2015; Vol.2:No.4, 208-15.

[18] Scott RD SS, McGowan JE. Applying Economic Principles to Health Care. Emerg Infect Dis. 2001:7(2):282-5.

[19] Owumi DB. Rational Choice Theory and the Choice of Healthcare Services in the Treatment of Malaria in Nigeria. Journal of Sociological Research. 2013; Vol.4.

[20] Onwujekwe O, Dike N, Ojukwu J, Uzochukwu B, Ezumah N, Shu E, et al. Consumers stated and revealed preferences for community health workers and other strategies for the provision of timely and appropriate treatment of malaria in southeast Nigeria. Malaria Journal. 2006; 5:117 